Situs Jurnal : $\underline{\text { http://ejournal.stiepancasetia.ac.id/index.php/jieb }}$

Jilid 5 Nomor 3 November 2019

Hal $301-311$

\title{
ANALISIS STRATEGI PEMASARAN DALAM UPAYA MENINGKATKAN VOLUME PENJUALAN PADA PT. TITIPAN KILAT BANJARMASIN
}

\author{
Jaya Bahwiyanti* dan Nor Laili
}

Abstract: The purpose of this research is to identify what strategy applied by PT. Titipan Kilat Banjarmasin and give thought contribution about marketing strategy that must be done to increase sales volume at PT. Titipan Kilat Banjarmasin uses the theory of Philip Khotler Marketing Mix 7P. Data analysis technique used in this research is descriptive is used if researchers want to give a more complete picture of a phenomenon, whether it is a phenomenon that is currently underway and phenomena that have occurred in the past. The results showed that the effectiveness of marketing strategy Product, Promotion, People who influence in increasing sales volume at PT. Titipan Kilat Banjarmasin.

\section{Keywords: marketing strategy, marketing mix 7P, PT. Titipan Kilat Banjarmasin}

Abstrak: Tujuan penelitian ini adalah untuk mengidentifikasi strategi yang diterapkan PT. Titipan Kilat Banjarmasin dan memberikan solusi mengenai Strategi pemasaran yang harus dilakukan agar meningkatkan volume penjualan pada PT. Titipan Kilat Banjarmasin menggunakan teori Philip Khotler bauran pemasaran 7P. Teknik analisa data yang digunakan dalam penelitian ini adalah deskriptif yang digunakan peneliti dalam memberikan gambaran yang lebih lengkap mengenai suatu fenomena, baik itu fenomena yang sedang berlangsung saat ini maupun fenomena yang sudah terjadi di masa lalu. Hasil penelitian menunjukan bahwa belum efektifnya strategi pemasaran Product, Promotion, People yang berpengaruh dalam meningkatkan volume penjualan pada PT. Titipan Kilat Banjarmasin.

Kata kunci: Strategi Pemasaran, bauran pemasaran 7P, PT. Titipan Kilat Banjarmasin

\section{Latar Belakang}

Perkembangan industri jasa pengiriman mengalami peningkatan yang cukup pesat, tidak hanya memudahkan masyarakat tapi juga bagi pelaku bisnis. Para pelaku bisnis, terutama pelaku bisnis online atau e-commerce menggunakan jasa pengiriman barang untuk mengirimkan barang customernya ke seluruh Indonesia hingga ke luar negeri.

Melihat banyaknya jasa pengiriman barang yang ada di Indonesia membuat para pelaku bisnis perlu menentukan jasa pengiriman yang tepat untuk digunakan, seperti mengetahui kredibilitas jasa pengiriman, pelayanan yang profesional, kecepatan pengiriman, biaya pengiriman, kemudahan dalam menggunakan jasa, serta asuransi atau jaminan pengiriman yang ditawarkan menjadi faktor yang harus dipertimbangkan dalam menggunakan jasa pengiriman barang.

Industri jasa pengiriman barang di Indonesia dikuasai oleh beberapa merek besar, antara lain TIKI, Pos Indonesia, JNE, DHL, FedEx, dan berbagai perusahaan jasa pengiriman lainnya. Munculnya persaingan dalam dunia bisnis yang semakin kompetitif mendorong perusahaan untuk cerdik menggunakan strategi dalam memenangkan persaingan. 
PT. Titipan Kilat ( TIKI) Banjarmasin merupakan salah satu perusahaan ekpedisi jasa pengiriman yang ada di Indonesia, kualitas pelayanan sangatlah diutamakan untuk semua jenis usaha yang diberikan perusahan kepada konsumen. Tuntutan kompetisi antar perusahaan ekspedisi jasa pengiriman semangkin mendesak, sehingga memaksa perusahaan untuk terus meningkatkan daya saing agar tidak tergeser oleh perusahaan-perusahaan ekspedisi lainnya, terutama dalam merenggut pangsa pasar dalam tingkat kualitas pelayanan yang sesuai dengan tuntutan dan kebutuhan pelanggan.

TIKI memiliki dua layanan produk pengiriman barang yaitu DOM dan INT. DOM merupakan layanan pengiriman barang untuk wilayah domestik (seluruh Indonesia), sedangkan INT merupakan layanan pengiriman barang ke seluruh dunia. Selain itu, Tiki juga memiliki beragam varian layanan produk yang disesuaikan dengan kebutuhan customer.

Strategi pemasaran merupakan hal yang penting untuk di lakukan TIKI Banjarmasin, Peneliti tertarik memilih objek penelitian karena presentase volume penjualannya mengalami Fluktuasi dan bahkan mengalami penurunan sebanyak $-4,5 \%$. Oleh sebab itu di perlukan strategi pemasaran yang tepat oleh pihak perusahaan agar volume penjualan TIKI semakin meningkat.

\section{Kajian Literatur}

Menurut Kotler dan Keller (2012:5) Manajemen pemasaran adalah sebagai seni dan ilmu memilih pasar sasaran dan meraih, mempertahankan, serta menumbuhkan pelanggan dengan menciptakan, menghantarkan, dan mengkomunikasikan nilai pelanggan

Menurut Assauri (2013:12) manajemen pemasaran adalah kegiatan menganalisis, merencanakan, melaksanakan dan mengendalikan program-program yang disusun dalam pembentuan, pembangunan, dan pemeliharaan keuntungan dari pertukaran/transaksi melalui sasaran pasar dengan harapan untuk mencapai tujuan organisasi (perusahaan) dalam jangka panjang.

Manajemen pemasaran memiliki tujuan dan fungsi sebagai berikut. Tujuan manajemen pemasaran adalah:

1. Untuk mendapatkan keuntungan atau laba

2. Mendapatkan konsumen atau pelanggan

3. Meningkatkan daya beli konsumen atau pelanggan

4. Memperkenalkan produk atau jasa yang dilakukan

5. Bersaing dengan perusahaan atau produsen lain

Fungsi manajemen pemasaran:

1. Melakukan distribusi barang atau jasa

2. Melakukan riset konsumen

3. Menetapkan harga

4. Mengembangkan produk

5. Memberikan layanan kepada pelanggan

Strategi pemasaran menurut Kotler (2012:19) merupakan pola pikir yang akan di gunakan untuk mencapai tujuan pemasaran pada suatu perusahaan, bisa mengenai strategi spesifik untuk sasaran pasaran, penetapan posisi, bauran pemasaran, dan besarnya sebuah pengeluaran pemasaran.

Difinisi lain dikemukakan oleh Assauri (2014:198) dimana "Strategi pemasaran adalah himpunan asas secara tepat, konsisten dan layak dilaksanakan oleh perusahaan guna mencapai sasaran pasar yang dituju (target market) dalam jangka panjang dan tujuan perusahaan jangka 
panjang (objectives) dalam situasi persaingan tertentu", ada tiga faktor utama yang menyebabkan terjadinya perubahan strategi dalam pemasaran yaitu:

1. Daur hidup produk

2. Posisi persaingan perusahaan dipasar

3. Situs Ekonomi

Menurut Kotler dan Keller (2016:47) Empat variable dalam kegiatan bauran pemasaran memiliki komponen yakni: produk, price, promotion dan place. Bauran pemasaran menurut Kotler dan Armstrong (2014:76) unsur-unsur bauran pemaaran dapat digolongkan menjadi empat dengan i masing-masing variable itu adalah:

1. Unsur produk (Product) adalah barang dan jasa perusahaan menawarkan dua target pasar.

2. Unsur harga (price) adalah jumlah pelanggan harus dibayar untuk memperoleh produk.

3. Unsur Promosi (promotion) adalah mencakup perusahaan produk tersedia untuk menargetkan pelanggan.

4. Unsur Tempat (place) adalah mengacu pada kegiatan berkomunikasi kebaikan produk dan membujuk pelanggan sasaran.

Seiring dengan perkembangan bauran pemasaran memiliki beberapa perangkat pemasaran tambahan seperti People (orang), Physical evidence (bukti fisik), dan Process (proses). Pengertian 7P menurut Kotler dan Amstrong dalam Tanzil (2014:7) yaitu:

1. Product (Produk) adalah mengelola unsur produk termasuk perencanaan dan pengembangan barang atau jasa yang tepat untuk dipasarkan dengan mengubah barang atau jasa yang ada dengan menambah dan mengambil tindakan yang lain yang mempengaruhi bermacammacam barang atau jasa.

2. Price (Harga) adalah suatu sistem manajemen perusahaan yang akan menentukan harga dasar yang tepat bagi produk barang atau jasa dan harus menentukan strategi yang menyangkut potongan harga, pembauaran ongkos angkut dan berbagi variable yang bersangkutan.

3. Place (Tempat) yakni memilih dan mengelola lokasi perdagangan yang dipakai untuk menyalurkan produk tersebut dan juga untuk melayani pasar sasaran, serta mengembangkan sistem distribusi untuk pengiriman dan perniagaan produk secara fisik.

4. Promotion (Promosi) adalah suatu unsur yang digunakan untuk memberitahukan dan membujuk pasar tentang produk yang baru pada perusahaan melalui iklan, penjualan pribadi, promosi penjualan maupun publikasi melalui saluran media-media komunikasi seperti media massa media cetak dan media elektronik.

5. People (Orang) adalah semua pelaku yang memainkan peranan penting dalam penyajian produk atau jasa sehingga dapat mempengaruhi persepsi pembelian. Elemen dari orang adalah pegawai perusahaan, konsumen dan konsumen lain. Semua sikap dan tindakan karyawan, cara berpakaian, dan penampilan karyawan memiliki pengaruh terhadap keberhasilan penyampaian produk atau jasa yang dijual

6. Physical evidence (Bukti Fisik) merupakan hal nyata yang turut mempengaruhi keputusan konsumen untuk membeli dan menggunakan produk yang ditawarkan. Unsur yang termasuk dalam secara fisik antara lain lingkungan atau bangunan fisik, peralatan, perlengkapan, logo, warna dan barang-barang lainnya

7. Process (proses) adalah semua prosedur aktual, mekanisme dan aliran aktivitas yang digunakan untuk menyampaikan produk. Elemen proses ini memiliki arti suatu untuk menyampaikan produk. Proses dalam produk merupakan faktor utama dalam bauran pemasaran seperti pelanggan produk akan senang merasakan sistem penyerahan produk sebagai bagian produk itu sendiri. 
Penelitian ini memiliki penelitan-penelitian terdahulu sebagai pedoman. Beberapa penelitian terdahulu yang menunjang penelitian ini meliputi:

1. Mega Pittriani tahun 2013 dengan judul "Penerapan Strategi Pemasaran PT. TIKI JNE agen utama depok dalam meningkatkan daya Tarik konsumen". Hasil analisa dapat di simpulkan bahwa berdasarkan bauran pemasaran perusahaan PT. TIKI JNE dapat melakukan pemasaran dengan efektif dan efesien di karenakan sistem dan basis teknologi yang sudah terdukung, dan lokasi yang mendukung menjadi salah satu point lebih di hadapan konsumen. Perbedaanya dengan penelitian yang akan saya lakukan adalah menggunakan bauran pemasaran untuk meupayakan meningkatkan volume penjualan pada PT. Titipan Kilat Banjarmasin.

2. Ariska putri Mayasari tahun 2014 dengan judul "Strategi pemasaran dalam meningkatkan volume penjualan TIKI jl. Wahid hasim No 16 E Salatiga“. Mengindentifikasi faktor - faktor masalah yang membuat menurunya volume penjualan, dan hasilnya ada faktor kurangnya promosi yang mengakibatkan penurunan dalam volume penjualan. Perbedaannya dengan penelitian yang akan saya lakukan adalah perbedaan tempat, waktu dan masalah yang terjadi pada PT. Titipan kilat Banjarmasin .

3. Rina Rahmawati Tahun 2014 dengan Judul "Strategi Pemasaran PT. Pos Indonesia (persero) Kantor Banjarbaru Dalam Meningkatkan Kualitas Pelayanan Kepada Masyarakat" Banjarbaru. Dalam penerapan bauran pemasaran untuk meningkatkan volume penjualan dapat ditemukan beberapa faktor yang membantu meningkatkan volume penjualan, yaitu aspek produk (produk yang berkualitas tinggi), aspek tempat (tempat produksi yang mempunyai dua lokasi mempermudah akses bahan pokok ke rumah produksi). Sedangkan untuk aspek harga dan promosi, Masih harus ada perbaikan dan peningkatan secara berkala.perbedaan dengan penelitian saya yang lebih berfokus pada produk layanan jasa yang berpengaruh dalam meningkatkan volume penjualan pada perusahaan yang akan saya teliti.

\section{Metode Penelitian}

Dalam melakukan penelitian ada dua jenis data yang digunakan dalam penelitian ini adalah data kualitatif dan kuantitatif.

1. Data Kuantitatif adalah data yang bisa diselidiki secara langsung dan bisa dihitung dengan menggunakan alat ukur sederhana.Dengan kata lain, data kuantitatif merupakan tanda-tanda kebenaran (fakta) yang nyata dan dapat ditangap oleh panca indera. Misalnya, Jumlah pegawai, besarnya gaji, lamanya pendidikan dan lain-lain.

2. Data Kualitatif adalah data yang tidak dapat diteliti secara langsung. Data ini menunjukan kualitas atau mutu dari sesuatu yang ada berupa keadaan, proses. Kejadian atau peristiwa, dan lain-lain yang dinyatakan dalam bentuk pernyataan (perkataan). Misalnya data mengenai intelegensi, keterampilan, aktivitas sosiabilitas, kejujuran dan lain-lain.

Sumber data dalam penelitian ini adalah data primer dan data sekunder

1. Data Primer yaitu data yang didapat langsung dari objek penelitian dan diolah sendiri oleh penulis.

2. Data Sekunder yaitu data yang didapat dari objek penelitian yang merupakan data pendukung, seperti data penjualan, target penjualan, sejarah perusahaan, struktur organisasi, jumlah karyawan dan sebagainya yang tidak dapat diolah kembali oleh penulis 
Teknik analisa data yang digunakan dalam penelitian ini adalah secara deskriptif, yaitu penyusunan dan penulisan dikemukakan sebagai mana adanya, sehingga tidak bertentangan dengan ketentuan yang berlaku.

Data yang diperoleh dianalisi dengan menggunakan dasar dasar teoritis yang diperoleh penulis dalam penelitian kepustakaan dan selanjutnya menyusun, mengolah data tersebut dalam bentuk karya tulis.

\section{Hasil Penelitian}

Seiring dengan perkembangan perindustrian dan perdagangan kebutuhan manusia yang serba instan,perkembangan sentra bisnis, banyak perusahaan yang menawarkan jasa pengiriman barang seperti TIKI, JNE, POS,DHL,JNT Logistics, yang menyediakan berbagai produk layanan, seperti jasa pengiriman uang, barang, dokumen, serta surat-surat berharga yang sudah dikemas terlebih dahulu dengan berbagai macam pilihan tarif yang sesuai dengan kebutuhan konsumen. Penerapan bauran pemasaran pada TIKI Banjarmasin sangat berpengaruh terhadap peningkatan volume.

Tabel 1. Presentase Volume Penjualan PT. Titipan Kilat Banjarmasin Periode Januari s/d September 2017

\begin{tabular}{llrc}
\hline \multicolumn{1}{c}{ Bulan } & $\begin{array}{l}\text { Total } \\
\text { (Rp) }\end{array}$ & $\begin{array}{c}\text { Value Penurunan / Kenaikan } \\
\text { penjualan ( RP ) }\end{array}$ & Presentase Penjualan \\
\hline Januari & 140.312 .725 & & \\
\hline Februari & 143.194 .350 & 2.881 .625 & $2 \%$ \\
\hline Maret & 144.261 .350 & 1.067 .000 & $0,7 \%$ \\
\hline April & 149.467 .700 & 5.206 .350 & $3,6 \%$ \\
\hline Mei & 133.705 .825 & -15.761 .875 & $-10,5 \%$ \\
\hline Juni & 151.310 .200 & 17.604 .375 & $13,2 \%$ \\
\hline Juli & 151.262 .600 & -47.600 & $-0,3 \%$ \\
\hline Agustus & 142.039 .850 & -9.222 .750 & $-6,09 \%$ \\
\hline September & 133.911 .325 & -8.128 .525 & $-5,7 \%$ \\
\hline Oktober & 136.192 .200 & 2.280 .875 & $6,7 \%$ \\
\hline Total & 1.425 .658 .000 & -4.120 .525 & $-2,9 \%$ \\
\hline
\end{tabular}

Dari tabel 1 menunjukan Nilai penurunan dan kenaikan penjualan jasa pengiriman barang pada tahun 2017 dalam total penjualan produk layanan REG, ECO, ONS, TDS, dan SDS. Penjualan pada TIKI Banjarmasin mengalami peningkatan penjualan yang cukup signifikan pada tahun 2017 pada bulan Juni yakni penjualan nilai sebesar 13,2\% dan mengalami penurunan yang signifikan pada bulan Mei sebesar -10,5\%.

\section{Diskusi}

Strategi pemasaran yang selama ini diterapkan Pada PT. TIKI Banjarmasin dapat dijabarkan sebagai berikut:

1. Product (Produk)

PT. Titipan Kilat Banjarmasin memiliki 9 produk Layanan yang ditawarkannya kepada customer dan Data layanan pesaing TIKI yaitu JNE seperti ditunjukkan pada Tabel 2 dan 3.

\section{Price (Harga)}

PT. Titipan Kilat Banjarmasin memberlakukan minimum charge untuk setiap pengiriman adalah $1 \mathrm{Kg}$. Meskipun secara aktual berat barang kurang dari $1 \mathrm{Kg}$, dan juga memberlakukan pembulatan keatas setiap berat $1,3 \mathrm{~kg}$ maka berat pengiriman menjadi $2 \mathrm{~kg}$. 
Bahwiyanti \& Laili, Analisis Strategi Pemasaran Dalam Upaya Meningkatkan Volume Penjualan Pada....

Tabel 2. Varian Produk TIKI

\begin{tabular}{|c|c|c|c|}
\hline Produk & No & Varian Layanan & Keterangan \\
\hline \multirow[t]{6}{*}{$\begin{array}{l}\text { DOM } \\
\text { (Domestik) }\end{array}$} & 1 & $\begin{array}{l}\text { SDS } \\
\text { (Same Day Services) }\end{array}$ & Paket yang dikirimkan hari ini akan segera tiba pada hari yang sama \\
\hline & 2 & $\begin{array}{l}\text { ONS } \\
\text { (One Night Services) }\end{array}$ & Paket yang dikirimkan hari ini akan segera tiba keesokan harinya \\
\hline & 3 & $\begin{array}{l}\text { TDS } \\
\text { (Two Days Services) }\end{array}$ & $\begin{array}{l}\text { Waktu pengiriman paket hanya membutuhkan } 2 \text { (dua) hari saja untuk tiba } \\
\text { di tempat tujuan }\end{array}$ \\
\hline & 4 & $\begin{array}{l}\text { HDS (Holiday Day } \\
\text { Services) }\end{array}$ & Pengiriman paket dengan pengantaran saat hari libur \\
\hline & 5 & REG (Reguler) & $\begin{array}{l}\text { Paket yang dikirimkan hari ini akan segera tiba dalam waktu kurang dari } 7 \\
\text { hari kerja }\end{array}$ \\
\hline & 6 & ECO (Economy) & $\begin{array}{l}\text { Pengiriman paket dengan konsep ramah biaya, dan disesuaikan dengan } \\
\text { kebutuhan }\end{array}$ \\
\hline \multirow[t]{2}{*}{$\begin{array}{l}\text { INT } \\
\text { (Internasional) }\end{array}$} & 7 & PRS (Priority Services) & $\begin{array}{l}\text { Menangani titipan paket yang istimewa secara personal oleh tenaga } \\
\text { profesional terpilih }\end{array}$ \\
\hline & 8 & $\begin{array}{l}\text { WDX (World Document } \\
\text { Express) }\end{array}$ & Menangani pengiriman dokumen atau surat ke seluruh dunia \\
\hline $\begin{array}{l}\text { WPX (World } \\
\text { Parcel } \\
\text { Express) }\end{array}$ & 9 & $\begin{array}{l}\text { WPX (World Parcel } \\
\text { Express }\end{array}$ & Menangani pengiriman parcel atau paket ke seluruh dunia \\
\hline
\end{tabular}

Sumber: www.tiki-online.com

Tabel 3. Layanan Pengiriman Pesaing

\begin{tabular}{|c|c|}
\hline Varian layanan & Keterangan \\
\hline SS (Super Speed) & $\begin{array}{l}\text { Pengiriman Paket atau Dokumen peka waktu yang harus di berangkatkan sesegera mungkin di luar jadwal rutin dan } \\
\text { rute JNE. }\end{array}$ \\
\hline YES (Esok Sampai) & $\begin{array}{l}\text { Pengiriman Premium dengan Target kiriman sampai di tujuan pada keesokan harinya termasuk pada hari munggu } \\
\text { atau libur nasional. }\end{array}$ \\
\hline$\overline{\text { REG (Reguler) }}$ & Pengiriman Paket cepat, aman, dan handal sampai ke pelosok Indonesia. \\
\hline $\begin{array}{l}\text { OKE (Ongkos Kirim } \\
\text { Ekonomis) }\end{array}$ & Pengiriman barang berukuran besar atau berat dengan harga ekonomis. \\
\hline $\begin{array}{l}\text { PESONA (Pesanan } \\
\text { Oleh-Oleh Nusantara) }\end{array}$ & $\begin{array}{l}\text { Pengiriman ragam maknan khas nusantara dapat di pesan secara online dan akan did atangkan langsung dari daerah } \\
\text { asalnya. }\end{array}$ \\
\hline \multicolumn{2}{|c|}{ JLC (JNE Loyalty Card) Program Keanggotaanyang di tunjukan kepada pelanggan setia JNE. } \\
\hline \multicolumn{2}{|c|}{$\begin{array}{l}\text { JESIKA (Jemputan ASI Penjemputan ASI dari tempat AKtivitas hingga pengantaran ke tempat tujuan. } \\
\text { seketika) }\end{array}$} \\
\hline \multicolumn{2}{|l|}{$\begin{array}{l}\text { PELIKAN (Pengiriman J } \\
\text { Lintas Kawasan) }\end{array}$} \\
\hline Money Remittance & $\begin{array}{l}\text { JNE Money Remittance adalah layanan pengiriman uang oleh JNE yang bekerjasama d } \\
\text { dalam bidang pengiriman uang, Western Union. }\end{array}$ \\
\hline \multicolumn{2}{|c|}{$\begin{array}{l}\text { JNE PIPO (JNE Pick Up Layanan alternative pelanggan dalam proses penerimaan kiriman. } \\
\text { Point) }\end{array}$} \\
\hline @BOX & Layanan Pengemasan kiriman sesuai persyaratan pengiriman Udara. \\
\hline DIPLOMAT & $\begin{array}{l}\text { Layana pengantaran peka waktu atas barang berharga/bernilai tinggi atau dokumen penting yang menuntut } \\
\text { pengamanan optimal. }\end{array}$ \\
\hline $\begin{array}{l}\text { JOP }(\text { JNE Online } \\
\text { Payment })\end{array}$ & $\begin{array}{l}\text { Layanan Pemesana atau pembelian dan pembayaran tiket seperti Kereta Api dan pembayayaran tagihan PLN, } \\
\text { TELKOM, dan Speedy melalui JNE. JOP tersedia di berbagai cabang di Indonesia. }\end{array}$ \\
\hline $\begin{array}{l}\text { JOB (JNE Online } \\
\text { Booking) }\end{array}$ & $\begin{array}{l}\text { Layanan Pemesanan tiket pengiriman JNE secara online dengan bisa mengisi resi pengiriman dan melakukan } \\
\text { pembayaran secara online dan kapan saja dan di mana saja di website www.booking.jne.co.id }\end{array}$ \\
\hline JTR (JNE Trucking) & $\begin{array}{l}\text { JNE menyediakan armada truck berjenis Double-Decker untuk memenuhi kebutuhan pelanggan dalam pengiriman } \\
\text { dimana setiap paket di-handle denganpelayanan khusus agar lebih aman serta meminimalisir resiko kerusakan pada } \\
\text { saat proses pengiriman. }\end{array}$ \\
\hline $\begin{array}{l}\text { INTERNATIONAL } \\
\text { SERVICE }\end{array}$ & JNe menawarkan pengiriman cepat dan mudah dalam pengiriman keseluruh dunia. \\
\hline$\overline{M Y J N E}$ & $\begin{array}{l}\text { Aplikasi yang berbasis Androidyang terhubung dengan nomor telpon pelanggan JNE, baik sebagai pengirim } \\
\text { maupun sebagai penerima. }\end{array}$ \\
\hline$\overline{P O P B O X}$ & $\begin{array}{l}\text { tanpa harus berada di rumah atau di kantor ketika barang kiriman anda t } \\
\text { g di lokasi loker terdekat. }\end{array}$ \\
\hline
\end{tabular}

Sumber: www.jne.co.id

JIEB, Jilid 5, No 3, November 2019 ISSN Online 2615-2134 
Rumus yang digunakan lewat udara yaitu:

(Besaran Kg) * Harga per-1 Kg sesuai jarak pengiriman = (Panjang * Lebar * Tinggi : 6000) * Harga per-1 Kg

Jadi, Besaran Kg $=60$ X 30 X $40: 6000=12 \mathrm{Kg}$. Sehingga total perhitungannya menjadi $12 \mathrm{Kg} * \mathrm{Rp} 25.000$,- (semisal tarif ONS per $1 \mathrm{Kg}$ Banjarmasin ke Surabaya) = Rp. 300.000,Meskipun pada kenyataannya bobot barang cuma $5 \mathrm{Kg}$ misalkan.Artinya perlu dicatat, besar kemasan sangat mempengaruhi jumlah biaya.

Rumus yang digunakan lewat laut yaitu:

$($ Besaran Kg) * Harga per-1 Kg sesuai jarak pengiriman = (Panjang * Lebar * Tinggi : 5000) * Harga per-1 Kg

Jadi, Besaran Kg $=60$ X 30 X $40: 5000=14,4 \mathrm{Kg}$. Sehingga total perhitungannya menjadi $15 \mathrm{Kg}$ X Rp 18,000,- (semisal tarif ECO per $15 \mathrm{Kg}$ Banjarmasin ke surabaya) $=$ Rp. $270.000,-$

Rumus yang digunakan lewat darat yaitu:

$($ Besaran $\mathrm{Kg}) *$ Harga per-1 Kg sesuai jarak pengiriman = (Panjang * Lebar * Tinggi : 4000) * Harga per-1 Kg

Jadi, Besaran Kg $=60$ X 30 X $40: 4000: 2=9 \mathrm{Kg}$. Sehingga total perhitungannya menjadi $9 \mathrm{Kg} * \mathrm{Rp} 7.000$,- (semisal tarif ONS per $1 \mathrm{Kg}$ Banjarmasin ke Banjarbaru) = Rp. 63.000,-

Untuk packing kayu dan karung kebanyakan adalah barang elektronik yang rentan akan kerusakan sehingga diwajibkan untuk mempacking kayu, packing kayu juga mempengaruhi berat timbangan sehingga apabila berat barang nya $3 \mathrm{~kg}$ maka berat setelah di packing kayu adalah 2 kali berat awal atau 6 kg. Daftar harga TIKI Banjarmasin untuk ke seluruh kota di Indonesia dan daftar harga pesaing TIKI Banjarmasin, Serta daftar harga lengkap layanan TIKI Banjarmasin ditunjukkan pada Tabel 4.

\section{Place (Tempat)}

PT. Titipan Kilat Banjarmasin lokasinya berada di Jalan Ahmad Yani Km 4.5.lokasi yang sangat strategis bagi pelanggan.Strategis yang di maksud merupakan gambaran bahwa tempat tersebut mudah dijangkau, konsumen.

PT. Titipan Kilat Banjamasin memiliki sub agen dan gerai-gerai yang tersebar di Banjamasin dengan tujuan agar memudahkan customer mengirimkan paket atau barangnya ke TIKI, adapun syarat untuk membuka sub agen dan gerai adalah minimal 10 kilometer atau kabupaten untuk sub agen dan minimal 100 meter untuk jarak gerai terdekat atau apabila setelah disurvey di daerah tersebut memiliki banyak potensi maka sub agen dan gerai bisa di buka kembali,

\section{Promotion (Promosi)}

Promosi yang dilakukan pihak PT. Titipan Kilat Banjarmasin sangatlah bervariasi. Berikut promosi yang sudah dilakukan PT. Titipan Kilat Banjarmasin:

a. Spanduk disetiap gerai-gerai pasti memiliki spaduk, untuk menginformasikan disitu adalah TIKI dan TIKI bisa melayani lewat udara, laut, maupun darat

b. Banner untuk menginformasikan produk terbarunya.

c. Brosur untuk menginformasikan untuk menjadi partner 
d. Aplikasi pada smartphone dengan basis IOS dan Android

e. Radio, pemasangan iklan pada saat bulan puasa.

f. Acara sosial, seperti Halal Bihalal, dakwah atau pengajian, kunjungan ke panti asuhan, kunjungan atau undangan dan kunjungan anak TK ke tiki yang bertujuan untuk mengenalkan anak-anak tentang proses pengiriman.

g. Jemputan Gratis, layanan terbaru PT. Titipan Kilat Banjarmasin ini melayani pelanggan yang menginginkan paketnya untuk di jemput dirumahnya cukup menghubungi nomor yang telah diberikan oleh PT. Titipan Kilat Banjarmasin.

Tabel 4. Daftar harga kiriman keseluruh ibukota di Indonesia TIKI dan TIKI JNE

TIKI BANJARMASIN

\begin{tabular}{|c|c|c|c|c|c|c|c|c|c|c|c|}
\hline No & Provinsi & ONS (Rp) & REG (Rp) & ECO (Rp) & SDS (Rp) & HDS (Rp) & REG & YES & OKE & SS & POPBOX \\
\hline 1 & Banda Aceh & 61.000 & 48.000 & 41.000 & - & - & 50.000 & - & 43.000 & - & - \\
\hline 2 & Medan & 52.000 & 42.000 & 32.000 & - & 62.000 & 44.000 & 58.000 & 38.000 & - & - \\
\hline 3 & Padang & 47.000 & 33.000 & 25.000 & - & 57.000 & 40.000 & 52.000 & 34.000 & - & - \\
\hline 4 & Palembang & 42.000 & 34.000 & 27.000 & - & 52.000 & 40.000 & 34.000 & 34.000 & - & - \\
\hline 5 & Bengkulu & 48.000 & 38.000 & 32.000 & - & 58.000 & 42.000 & 54.000 & 36.000 & - & - \\
\hline 6 & Pekanbaru & 45.000 & 39.000 & 32.000 & - & 57.000 & 42.000 & 55.000 & 36.000 & - & - \\
\hline 7 & Tanjung Pinang & 55.000 & 44.000 & 37.000 & - & - & 50.000 & - & 43.000 & - & - \\
\hline 8 & Bandar Lampung & 40.000 & 30.000 & 26.000 & - & 50.000 & 33.000 & 44.000 & 29.000 & - & - \\
\hline 9 & Jambi & 48.000 & 38.000 & 31.000 & - & 58.000 & 39.000 & 50.000 & 34.000 & - & - \\
\hline $\mathbf{1 0}$ & Pangkal Pinang & 46.000 & 38.000 & 33.000 & - & 56.000 & 42.000 & 54.000 & 36.000 & - & - \\
\hline 11 & Pontianak & 52.000 & 40.000 & 35.000 & & 62.000 & 41.000 & 53.000 & 35.000 & - & - \\
\hline 12 & Palangkaraya & 12.000 & 10.000 & 10.000 & - & - & 20.000 & 28.000 & 17.000 & 248.000 & - \\
\hline 13 & Banjarmasin & 5.000 & 5.000 & 5.000 & 20.000 & 15.000 & 6.000 & 8.000 & 5.000 & - & - \\
\hline 14 & Samarinda & 26.000 & 22.000 & 19.000 & & 46.000 & 22.000 & - & 19.000 & 413.000 & - \\
\hline 15 & Tanjung Selor & - & 42.000 & - & - & - & 44.000 & - & 38.000 & - & - \\
\hline 16 & Jakarta & 27.000 & 22.000 & 18.000 & 210.000 & 37.000 & 22.000 & 29.000 & 19.000 & 275.000 & 29.000 \\
\hline 17 & Bandung & 32.000 & 28.000 & 22.000 & - & 42.000 & 30.000 & 38.000 & 26000 & 468.000 & - \\
\hline 18 & Serang & 32000 & 26.000 & 23.000 & - & 42.000 & 26.000 & 36.000 & 23.000 & - & - \\
\hline 19 & Semarang & 38.000 & 28.000 & 23.000 & 230.000 & 48.000 & 31.000 & 41.000 & 27.000 & 550.000 & - \\
\hline 20 & Yogyakarta & 32.000 & 28.000 & 23.000 & 230.000 & 42.000 & 31.000 & 41.000 & 27.000 & 550.000 & - \\
\hline 21 & Surabaya & 25.000 & 20.000 & 18.000 & 210.000 & 39.000 & 21.000 & 28.000 & 18.000 & 248.000 & - \\
\hline 22 & Denpasar & 45.000 & 34.000 & 28.000 & - & 42.000 & 37.000 & 47.000 & 32.000 & 605.000 & - \\
\hline 23 & Mataram & 56.000 & $36.000 \quad 30.00$ & & - & 66.000 & 46.000 & 59.000 & 40.000 & - & - \\
\hline 24 & Kupang & 75.000 & $58.000 \quad 48.00$ & & - & - & 73.000 & - & 63.000 & - & - \\
\hline 25 & Manado & 81.000 & $56.000 \quad 48.00$ & & - & - & 62.000 & - & 53.000 & - & - \\
\hline 26 & Mamuju & - & $44.000-$ & & - & - & 83.000 & - & 71.000 & - & - \\
\hline 27 & Palu & 51.000 & $50.000 \quad 42.00$ & & - & - & 55.000 & - & 47.000 & - & - \\
\hline 28 & Kendari & 73.00 .0 & $48.000 \quad 40.00$ & & - & - & 66.000 & - & 57.000 & - & - \\
\hline 29 & Makassar & 58.000 & $34.000 \quad 28.00$ & & 280.000 & 68.000 & 46.000 & 59.000 & 40.000 & - & - \\
\hline 30 & Gorontalo & 76.000 & $52.000 \quad 44.00$ & & - & - & 64.000 & - & 55.000 & - & - \\
\hline 31 & Ambon & 81.000 & $58.000 \quad 47.00$ & & - & - & 74.000 & - & 63.000 & - & - \\
\hline 32 & Ternate & 78.000 & $60.000 \quad 51.00$ & & - & - & 75.000 & - & 64.000 & - & - \\
\hline 33 & Manokwari & - & $94.000-$ & & - & - & 303.000 & - & 258.000 & - & - \\
\hline 34 & Jayapura & 111.000 & $90.000 \quad 76.00$ & & - & - & 111.000 & - & 94.000 & - & - \\
\hline
\end{tabular}

Sumber: Dept Accounting PT. Titipan Kilat Banjarmasin

\section{People (Orang)}

Setiap perusahaan pasti memiliki orang yang menggerakkan atau menjalankan kegiatan usaha.begitu pula PT.Titipan Kilat Banjarmasin juga memiliki orang yang menjalankan usahanya, seperti sales counter, customer service, dan kurir.

\section{Process (Proses)}

Proses merupakan prosedur yang berisi terdapat tahapan-tahapan dari awal pembelian jasa sampai terjadinya kepuasan atau kekecewaan pelanggan. Hal ini sangat perlu di perhatikan karena menyangkut kualitas layanan sebuah perusahaan jasa. Berikut ini proses pelayanan barang atau paket berdasarkan produk yang ada: 
a. ONS (Over Night Service) untuk proses pelayanan produk ONS dimulai dari pelanggan datang pada saat TIKI Buka Jam 07.00, kemudian melakukan penimbangan barang atau paket. Kemudian, dilakukan pengisian data alamat maupun data pengirim barang atau paket oleh sales counter sampai pada proses pembayaran. Kemudian barang atau paket diletakan pada keranjang yang disediakan berdasarkan produknya.

b. TDS (Two Days Service) untuk proses pelayanan produk TDS dimulai dari pelanggan datang pada saat TIKI Buka Jam 07.00, kemudian melakukan penimbangan barang atau paket.

c. REG (Reguler) untuk proses pelayanan produk REG dimulai dari pelanggan datang pada saat TIKI Buka Jam 07.00, kemudian melakukan penimbangan barang atau paket. Kemudian, dilakukan pengisian data alamat maupun data pengirim barang atau paket oleh sales counter sampai pada proses pembayaran. Kemudian barang atau paket diletakan pada keranjang yang disediakan yaitu keranjang berwarna biru. Produk REG akan diangkut sama seperti produk ONS tetapi, produk REG akan ditahan selama 1 hari dan akan diberangkatkan pada hari selanjutnya.

d. SDS (Sameday Service) untuk proses pelayanan produk SDS akan aktif hanya senin sampai jumat yang dimulai dari pelanggan datang pada saat TIKI Buka Jam 07.00, kemudian melakukan penimbangan barang atau paket. Kemudian, dilakukan pengisian data alamat maupun data pengirim barang atau paket oleh sales counter sampai pada proses pembayaran. Produk SDS akan diangkut selama 2 kali sehari sampai pada jam tutupnya pada jam 10.00 dan akan langsung diberangkatkan pada jam 10.00 tersebut untuk sampai pada hari itu juga.

e. ECO (Economy) untuk proses pelayanan produk ECO dimulai dari pelanggan datang pada saat TIKI Buka Jam 07.00, kemudian melakukan penimbangan barang atau paket. Kemudian, dilakukan pengisian data alamat maupun data pengirim barang atau paket oleh sales counter sampai pada proses pembayaran. Kemudian barang atau paket diletakan pada keranjang yang disediakan yaitu keranjang berwarna warna biru. Produk ECO akan diangkut sama seperti produk ONS tetapi, produk ECO akan ditahan selama 2 sampai 3 hari dan akan diberangkatkan pada hari selanjutnya.

f. HDS (Holiday Service) untuk proses pelayanan produk HDS akan aktif pada hari sabtu dan sebelum tanggal merah yang dimulai dari pelanggan datang pada saat TIKI Buka Jam 07.00, kemudian melakukan penimbangan barang atau paket. Kemudian, dilakukan pengisian data alamat maupun data pengirim barang atau paket oleh sales counter sampai pada proses pembayaran. Kemudian barang atau paket diletakan pada keranjang yang disediakan yaitu keranjang berwarna Hijau. Produk HDS akan diangkut sama seperti produk ONS dan akan tutup produk pada jam 14.00.

g. INT'L (International Service) untuk proses pelayanan produk INT'L dimulai dari pelanggan datang pada saat TIKI Buka Jam 07.00, kemudian melakukan penimbangan barang atau paket. Kemudian, dilakukan pengisian data alamat maupun data pengirim barang atau paket oleh sales counter sampai pada proses pembayaran. Kemudian barang atau paket diinformasikan kebagian terkait atau bagian outgoing kalau ada pengiriman INT'L.

\section{Physical Evidence (Bukti Fisik)}

Physical Evidence (bukti fisik) meliputi penampilan fasilitas fisik seperti gedung dan ruangan pendukung jasa, tersedianya tempat parkir, kebersihan, kerapian, dan kenyamanan ruangan, kelengkapan peralatan komunikasi, dan penampilan karyawan. Bukti fisik pada PT. Titipan Kilat Banjarmasin yaitu memiliki gedung tempat pendukung jasa tersebut yang di dalamnya terdapat ruang yang disediakan untuk menjual jasa. 
Strategi pemasaran yang seharusnya dijalankan PT. Titipan Kilat Banjarmasin untuk meningkatkan volume penjualan meliputi:

\section{Product (produk)}

Dari segi produk PT. Titipan Kilat Banjamasin dapat mempertahankan produk-produk yang sudah ada tetapi jika dibandingkan dengan pesaingnya, seperti layanan PESONA (Pesanan Oleh-oleh Nusantara) dari pesaingnya berkerjasama dengan sentra oleh-oleh di Indoenesia yang sekarang sedang banyak bisnis kue dari artis-artis Indonesia. TIKI bisa mengembangkan Layanan sesuai kebutuhan pelanggan seperti melakukan kerjasama dengan situs belanja online yang sekarang banyak diminati olehkonsumen. Situs belanja online seperti Bukalapak, Tokopedia, Olx, dan Shopie adalah salah satu situs belanja online yang banyak diminati konsumen, TIKI dapat bekerjasama dengan perusahaan belanja online dalam pengiriman barang belanja keseluruh Indonesia, pada TIKI Banjarmasin dapat melakukan hal yang sama terhadap Online shop atau sentra oleh-oleh khas dari Kalimantan Selatan seperti pengiriman Batu Permata atau Berlian.

\section{Price(harga)}

Dari segi harga (price) PT. Titipan Kilat Banjamasin mempunyai harga nasional dan diskon untuk harga kiriman agar dapat disampaikan kepada pelanggan dan untuk menjadi daya tarik dan saing perusahaan lainnya, dan di bandingkan pesaingnya harga TIKI lebih murah.

\section{Place (Tempat)}

Dari segi tempat PT. Titipan Kilat Banjamasin bisa menambah sub agen dan gerai dan melihat dari potensi daerah tersebut. Survey terhadap daerah-daerah potensi agar secepatnya dilakukan pembukaan gerai, penawaran langsung didaerah tersebut bagi yang ingin bekerjasama dengan perusahaan.

\section{Promotion (Promosi)}

Dari segi promosi PT. Titipan Kilat Banjamasin bisa menambah promosinya lagi seperti mengenalkan produk yang sudah ada karena yang terjadi di lapangan pelanggan menyebut kata YES (Yakin Esok Sampai) dan itu adalah milik pesaingnya, dan juga mempromosikan nya di media cetak atau radio di perbanyak lagi mengingat TIKI juga memiliki produk baru yaitu Jemputan Gratis (we delivery your pack), kebijakan-kebijakan perusahaan yang dikeluarkan agar disampaikan kepada pelanggan, dan memberitahukan Aplikasi Smartpone dengan basis IOS dan Android yang mempermudah konsumen dalam pengiriman barang.

\section{People (Orang)}

Dari segi orang PT. Titipan Kilat Banjamasin perlunya Karyawan dapat mempromosikan atau memberitahukan kepada konsumen tentang Promosi yang sedang ada di TIKI Banjarmasin, layanan yang disediakan dan kebijakan-kebijakan dari perusahaan untuk pelanggan tersampaikan dengan baik. Dengan konsumen mengetahui promosi yang dilakukan oleh TIKI Banjarmasin dapat memarik minat konsumen untuk melakukan pengiriman barang melalui jasa TIKI dan membuat volume penjualan meningkat.

\section{Process (proses)}

Dari segi prosesPT. Titipan Kilat Banjamasin bisa lebih memperhatikan kembali petugas bagian sales counter, costumer service, outgoing, pick up dan incomingmalam sehingga bisa memberikan informasi estimasi kiriman, memilih barang transit atau inbound dan peningkatan daya tarik karyawan kepada pelanggan lebih menarik dan tertarik untuk 
memakai produk perusahaan. Untuk bagian pengantaran (courir) diharapkan dapat menyampaikan produk yang dipakai oleh pelanggan sesuai dengan estimasi produk tersebut.

7. Physical Evidence (bukti fisik)

Dari segi bukti fisik PT. Titipan Kilat Banjamasin agar lebih mempersiapkan logistik agar lebih cepat untuk stok logistik yang sudah habis terpakai untuk pengiriman kiriman, menambah kursi tunggu di kantor pusat Jl. A. Yani KM. 4,5 dan standar ruangan untuk gerai, dan penambahan Armada seperti roda empat maupun roda dua.

\section{Kesimpulan dan Keterbatasan Penelitian}

Dari pembahasan yang telah dilakukan terhadap hasil penelitia ini. Dapat ditarik kesimpulan dalam penelitian ini adalah sebagai berikut:

1. Strategi pemasaran yang diterapkan oleh TIKI Banjarmasin adalah strategi Produk (Product), harga (Price), promosi (Promotion), dan tempat (place).

2. Strategi pemasaran pada PT. Titipan Kilat Banjarmasin yang seharusnyaditerapkan atau ditingkatkan kembali yaitu strategi produk (Product), promosi (Promotion), orang (People), proses (Process)

Saran yang dapat dikemukakan adalah sebagai berikut:

1. PT. Titipan Kilat Banjarmasin diharapkan melakukan kerjasama pada perusahaanperusahaan belanja online dan kerjasama kepada sentra oleh-oleh khas Kalimantan seperti batu Permataatau Berlian.

2. Melakukan promosi dimediaelektronik maupun mediacetak dengan mencantumkan promosi potongan harga,

3. Diharapkan seluruh staf dibagian sales counter, costumer service dan courir dapat ditraining dalam hal pelatihan etika, soft skill

\section{DAFTAR PUSTAKA}

Alma, Buchori, 2007, Manajemen Pemasaran dan Pemasaraan Jasa, Alfabeta, Bandung.

Assauri, Sofjan, 2014, Manajemen Pemasaran, Raja GrafindoPersada, Jakarta Barat.

Buchori, Herry Achmad dan Djaslim Saladin, 2010, Manjamen Pemasaran, Erlangga, Surabaya.

Febrianto, Aditya Indra, 2014, Penerapan Strategi Pemasaran pada CV. Jaya Jati Tambang Trosno Jawa Timur, Univesitas Islam Malang.

Hidayat, Khuzaimy, 2015, Analisis Strategi Pemasaran Pada CV Batu Alam Abadi di kota Prabumulih Sumatra Selatan, Fakultas Ekonomi Universitas Sriwijaya.

Jauch, Lawrence R dan Glueck William F, 2010, Manajemen Pemasaran, Erlangga, Jakarta.

Kotler, Philip, dan Garry Amstrong, 2014, Principles Of Marketing, New Jersey : Pearson Prentice Hall, USA.

Lupiyodi, Ramabt, 2013, Manajemen Pemasaran Jasa, Salemba, Jakarta.

Megasari, 2011, Analisa Strategi Pemasaran untuk meningkatkan penjualan pada perusahaan batu gunung Cv. Batu Agung Mulia, Universitas Ahmad Yani Banjarbaru.

Salim, H.S, 2010, Hukum Pertambangan di Indonesia, Rajawali, Yogyakarta.

Simamora, Meiriska, 2014, Strategi pemasaran untuk meningkatkan volume penjualan pada perusahaan batu kapur PT. Wira Kencana, Universitas Lambung Mangkurat.

Sudjana, Nana, 2010, Dasar-Dasar Proses Belajar, Sinar Baru, Bandung.

Sugiyono, 2010, Metode Penelitian Pendidikan Pendekatan Kuantitatif dan Kualitatif, Alfabeta, Bandung

Suyanto, Muhammad, 2011, Strategi Pemasaran, Erlangga, Jakarta.

Swasta, Basu, 2014, ManajemenPemasaran Modern, BPFE, Yogyakarta. 